\title{
EXTREMUS NECESSITATIS CASUS E O IMPERIUM A PARTIR DA OBRA DE GIORGIO AGAMBEN
}

\author{
EXTREMUS NECESSITATIS CASUS E O IMPERIUM A PARTIR DE LA OBRA DE GIORGIO \\ AGAMBEN
}

Fernando Bretas Vieira Porto*

\section{RESUMO}

$\mathrm{O}$ autor filósofo italiano Giorgio Agamben em sua obra Estado de exceção revisita o pensamento teórico de um importante jurista e filósofo político do século XX, o alemão Carl Schmitt. Há uma evidente apreensão pelos estudiosos do tema em dispor sobre os limites e extensão de medidas excepcionais em momentos de caos ou anomia, desta forma, o sintético texto acadêmico busca indagar e se orientar por rastros temáticos relativos ao estado de exceção. A citada obra enuncia como a suspensão da ordem jurídica pode ser encarada como natural em momentos nos quais as estruturas públicas sofrem ameaças ou possíveis dissoluções, retomando assim o pensamento schimitiano. É com a extremus necessitatis casus que surge a interlocução sobre a decretação do estado de exceção. Perquirir sobre o entendimento, bem como a relação entre a anomia e a norma vigente pode ser inserida em um real contexto jurídico e é de suma importância para entender o manejo desses institutos na politização dos poderes republicanos na contemporaneidade. Fazer com que o poder judiciário possa "agir" como reflexo do superego da sociedade brasileira é também discutir a necessidade e alcance de uma convicção soberana ao se decidir sobre o estado de exceção.

PALAVRAS-CHAVE: Estado de exceção. Anomia. Soberano. Schmitt.

\section{RESUMEN}

El autor filósofo italiano Giorgio Agamben en su obra Estado de Excepción revisita el pensamiento teórico de un importante jurista y filósofo político del siglo XX, el alemán Carl Schmitt. Hay una evidente aprehensión por los estudiosos del tema en disponer sobre los límites y extensión de medidas excepcionales en momentos de caos o anomia, de esta forma, el sintético texto académico busca indagar y orientarse por rastros temáticos relativos al estado de excepción. La citada obra enuncia como la suspensión del orden jurídico puede ser considerada como natural en momentos que las estructuras públicas sufren amenazas o posibles disoluciones, retomando así el pensamiento schimitiano. Es con la extremus necesitas casus que surge a la interlocución sobre la decretación del estado de excepción. Por lo que se refiere al entendimiento, así como la relación entre la anomia y la norma vigente puede ser insertada en un real contexto jurídico es de suma importancia para entender el manejo de estos institutos en la politización de los poderes republicanos en la contemporaneidad. Hacer que el poder judicial pueda "actuar" como reflejo del superyó de la sociedad brasileña es también discutir la necesidad y alcance de una convicción soberana al decidir sobre el estado de excepción.

PALABRAS CLAVE: Estado de Excepción. Anomalía. Soberano. Schmitt.

\footnotetext{
* Mestre em direito público. Graduando em Filosofia pela PUC Minas. Professor universitário e advogado. Email: bretasvporto@gmail.com.
} 


\section{INTRODUÇÃO}

A questão que se pretende com este brevíssimo estudo é expor a situação-chave que ensejaria decretação do extremus necessitatis casus em um dito Estado Democrático de Direito, em face de um poder de imperium que poderá decidir sobre a aplicabilidade e extensão da exceção diante de uma anomia normativa.

O filósofo Giorgio Agamben identifica em Carl Schmitt a utilização de uma figura que em situações emergenciais decida em favor da preservação e salvação daqueles pertencentes ao império romano cristão. O guardião do imperium é o soberano, assim este possui a atribuição de resguardar e perpetuar o direito romano diante do caos, assumindo no estado de emergência limite a figura daquele que vai adiar o estabelecimento, em absoluto, do fim.

Para o filósofo italiano, à espreita da situação extrema, ao estado de exceção é permitido deslindar os fundamentos de validade do ordenamento jurídico e, ainda, julgar e dispor sobre a situação cotidiana. O Estado de Direito busca retardar ao limite a decretação da emergência, até por uma questão de soberania e da repartição de atribuições constitucionais, mas é de suma importância lembrar que só compete ao soberano "dizer" quando a ordenamento jurídico vigente já não disponibiliza nenhuma diretriz que se dedica a uma solução.

Nos tópicos elencados abaixo será possível identificar o momento que ocorre a ruptura, o tempo em que soberano se manifesta, transcendendo a imagem do império romano, para que em uma atividade e linguagem que vai além dos dizeres legislativos postos, possa decidir sobre o "caso" de extrema necessidade.

\section{EXTREMUS NECESSITATIS CASUS E O IMPERIUM}

Durante a República de Weimar (1919-1933), Carl Schmitt publica a importante obra Teologia política, sustentando que diante de uma situação de caos, de desordem no direito do imperium romano, onde subsiste a anomia, quem decidirá sobre o estado de exceção é o Soberano.

Ainda sobre a definição de soberania, Schmitt (1996, p.11) em Teologia política I, alude que, "se somente Deus é soberano, aquele que, na realidade terrena, age de modo incontestável, o soberano ou o povo, isto é, aquele que pode identificar-se, indubitavelmente, com o povo também é soberano". 
Dessa forma, somente o soberano poderá dispor sobre a vigência do estado excepcional, bem como os ditames para eliminá-lo. A locução usual é de que há um poder ilimitado, "em razão disso, também sempre se pergunta quem decide sobre as competências constitucionais não regulamentadas, ou seja, quem é competente quando a ordem jurídica não oferece resposta à questão da competência" (SCHMITT, 1996, p. 11).

Visto o argumento inicial, parece crível depositar a fé "soberana", diante do pandemônio civilizatório, na figura de alguém ou algo que retarde ao máximo a chegada profetizada descrita pelo Anticristo. Assim, diante de um evento avassalador e de caos, o soberano é aquele que poderá deter o tempo em curso e vocacionar a excepcionalidade da realização do direito. Para tanto, há certos autores que compreendem o soberano como aquele que poderá transitar pela zona de anomia do direito, sendo ele o próprio detentor do caos.

Observa-se que, no decorrer do período medieval, houve um esquecimento da associação entre o império cristão e o reino territorial. Essa desvinculação decorre do desmemoriamento da palavra grega vó inaugura e unifica a ordenação de sua posição (SCHMITT, 2014, p. 58). O esquecimento de todo significado (originário e assimilado na modernidade) da palavra nomos, isto é, sua localização e estrutura, parece ser resultado do emudecimento do Império Romano e da perda de seu sentido último.

Assim, diante do silêncio do Império, o estado de caos se aproxima, ficando mais evidente a inoperabilidade da luta por Roma, fortificando o estado da anomia. Por meio de um deslocamento de um novo paradigma, Agamben (2004, p. 88) sustenta que "a cisão entre o poder soberano e seu exercício corresponde exatamente à cisão entre normas do direito e normas de realização do direito [...]”.

Seguindo seu raciocino, Schmitt (1996, p. 92) esboça a figura daquele que deve decidir diante do caos, e sustenta:

A exceção é o que não se pode acrescentar; ela subtrai-se à constituição geral, mas ao mesmo tempo revela um elemento formal jurídico específico, em sua pureza absoluta, que é a decisão. O caso excepcional só entra na sua forma absoluta quando, primeiro, é criada uma situação na qual as normas jurídicas possam ser validadas. Toda norma geral exige uma condição normal das relações de vida, nas quais ela tem que encontrar a sua aplicação tipificada e submetê-la à sua regulamentação normativa. A norma precisa de um meio homogênio. Essa normalidade efetiva não é só uma "pressuposição externa" que pode ser ignorada pelo jurista; ela pertence à sua validade imanente. Não existe norma aplicável no caos. 
É importante conceber que Schmitt está enveredando nos estudos para poder compreender que, diante da anomia legal e da exceção, há a figura daquele que decide em nome da autopreservação e que elimina a norma romana vigente, mas entendendo que a exceção continua acessível à observância jurídica.

Com a pretensão de normatizar o real, o Soberano, aquele que detém o poder de imperium, maneja e instrumentaliza a fim de:

\begin{abstract}
A aporia do lócus da necessidade, aquela que corresponde também ao da exceção o estar dentro e fora da ordem jurídica -, Schmitt pôde resolver justamente com a figura do soberano, pois este, ao estar dentro e fora da ordem jurídica, é quem garantiria a ancoragem do estado de exceção ao ordenamento jurídico. Se o soberano se circunscrevesse completamente à ordem jurídica, a decisão estaria restringida à norma jurídica, impossibilitada de versar sobre a exceção, de constituí-la. Portanto, apesar de fazer parte do ordenamento jurídico e, assim, garantir a ancoragem jurídica do estado de exceção, o soberano deve, por outro lado, estar fora, libertando-se das amarras advindas do direito, para que, decidindo sobre (über) a exceção, realize o milagre assegurador das relações normais da vida. Uma vez que a normatividade jurídica se encontra suspensa em virtude da decisão soberana, o soberano, por também deve se encontrar dentro do ordenamento jurídico, garante o respaldo jurídico da situação excepcional. (MARTINS, 2015, p. 862).
\end{abstract}

Como efetivar o debate e a decisão sobre a competência e o alcance da excepcionalidade, se não há em vigor uma estrutura lógico-jurídica válida e eficaz para suprimir ou retardar o caos? A soberania estatal é reconhecida com o monopólio da decisão, com o alcance daquele que decreta a emergência. Assim, ao que parece, a excepcionalidade entorpece todos os esquemas e estruturas lógicas e jurídicas, cristalizando a desmedida e coercitiva força estatal.

Em uma entrevista cedida em abril de 2018 para o jornal El País, o filósofo Giorgio Agamben sustenta que o estado de exceção saiu do seu campo semântico e está inserido no campo da "normalidade" do Estado dito de Direito:

O estado de exceção era um dispositivo provisório para situações de perigo. Hoje se tornou um instrumento normal de governo. Com a desculpa da segurança diante do terrorismo, se generalizou. A exceção, por isso se chamava estado de exceção, é norma. O terrorismo é inseparável do Estado porque define o sistema de governo. Sem o terrorismo, o sistema atual de governo não poderia funcionar. Há dispositivos como o controle das impressões digitais, ou o escaneamento que te fazem nos aeroportos, que foram adotados para controlar os criminosos e agora são aplicados a todos. Da perspectiva do Estado, o cidadão se transformou em um terrorista virtual. Do contrário, não se explica o acúmulo de câmeras que nos vigiam em todas as partes. Somos tratados como criminosos virtuais. O cidadão é um suspeito, numerado, como em Auschwitz, onde cada deportado tinha seu número. 
A tese schmittiana ganha relevância nos dias atuais pelo constante esfacelamento das instituições legislativas, que mesmo com a deficiência de representatividade estrutural, não consegue reordenar o estado de caos e anomia legiferante. É curioso mencionar que a "identificação entre o soberano e lei representa, pois, a primeira tentativa de afirmar a anomia do soberano e, ao mesmo tempo, seu vínculo essencial com a ordem jurídica" (AGAMBEN, 2004, p. 107).

O soberano, em uma leitura schmittiana, pode ser notado como um metassujeito, um ente público e supraindividual, com um lugar de "ação" e "fala" a ser ocupado no bojo do ordenamento jurídico estatal, do mesmo modo que está localizado acima dele (D’URSO, 2016, p. 17).

Ao que parece, o Poder Judiciário tem assumido a postura de "super-ego" da sociedade que se encontra órfã, e que assim decide sob o estado de anomia legislativa, sobre a vigência de um inegável estado de exceção. Não é difícil imaginar o judiciário, um órgão de instância constitucional, assumir as vestes de "algo ou alguém" que irá fazer a mediação no caos. O filósofo italiano aduz que "o aporte específico da teoria schmittiana é exatamente o de tornar possível tal articulação entre o estado de exceção e a ordem jurídica" (apud SCHMITT, 2014, p. 54).

O autor Gilmar Mendes (2007, p.11) na apresentação da obra em português de Carl Schmitt $O$ guardião da constituição, trazendo a disputa intelectual sobre quem deveria ser o guardião da Constituição, diz que "segundo Schmitt, a criação ou o reconhecimento de um Tribunal Constitucional, por outro lado, transfere poderes de legislação para o judiciário, politizando-o e desajustando o equilíbrio do sistema constitucional do Estado de Direito".

A noção de guardião da Constituição perpassa a ideia subliminar de quem ou algo poderá ter o "dizer último" do direito vigente. Destacando o caráter e o momento histórico da formulação teórica de Schmitt, o mesmo afirma que "em verdade, o ato do Führer foi o exercício de uma autêntica judicatura. Ele não está sujeito à justiça, ele mesmo foi justiça suprema" (SCHMITT, 2011, p. 179).

Nesta esteira teórica, desenvolvida por Giorgio Agamben, oportuno é o trecho da obra O Führer protege o direito: sobre o discurso de Adolf Hitler no Reichstag em 13 de julho de 1934 redigido, assim, por Schmitt (2011, p. 178):

O Führer protege o direito do pior abuso, quando ele, no instante do perigo, cria o direito sem mediações, por força da sua liderança (Führertum) e enquanto Juiz 
Supremo. "Nessa hora fui responsável pelo destino da nação alemã e com isso Juiz

Supremo do povo alemão". O verdadeiro líder [Führer] sempre é também juiz.

O Estado não poderá ser um simples patrono declaratório da sociedade, uma vez que não refletiria o poder de imperium. O Soberano, aquele que decide sobre o estado de exceção, a fim de expurgar todo caos e anomia vivenciado naquele momento histórico pelo imperium (representando o direito romano), só poderia ser representado pela figura do Führer.

\section{CONSIDERAÇÕES FINAIS}

A brevidade do texto aqui apresentado não possui, nem de longe, a pretensão de debater longamente tão profícua temática, mas tem o intento de suscitar no leitor interessado uma abordagem filosófica, política e de direito, para que futuramente possa emergir uma contribuição importante na pesquisa acadêmica brasileira.

Nos dias atuais verifica-se em diversos setores da sociedade (acadêmica ou não acadêmica), a disseminação do uso impróprio e até irresponsável do termo "estado de exceção". Ocorre que descrições e manifestos corriqueiros em prol de um discurso de um direito que assenta suas aparições no liame da exceção, logo, com viés não democrático, oculta a verdadeira complexidade do tema aqui proposto. É imperiosa a necessidade do aprofundamento nos estudos, bem como no resgate de certos autores, que por vezes são nominados como "fascistas", "nazistas", “comunistas", “capitalistas", “antidemocráticos", "conservadores", entre outras imputações. Esse descuido impossibilita que parte da comunidade acadêmica tenha acesso as suas obras, não desenvolva artigos e debates que possam contribuir a temas que são extremamente caros e relegados por toda modernidade.

Ao mesmo tempo em que os ditos articuladores da pós-modernidade encampam o ideal de não nominar, discorrem sobre a imprecisão de conceituar algo, da rotulação como meio de silenciar o outro, podem incorrer na contradição de não permitirem que o que está oculto se desvele e possa demonstrar o que verdadeiramente é. O conhecimento se dá pela busca, pelo desocultamento do objeto. Assim, não é crível elencar ou pôr em pauta a biografia do autor aqui abordado, mas o que interessa a nós pesquisadores (de maneira mais profunda) é sua contribuição teórica para um momento político mundial de grande instabilidade e consequentes incertezas. 
Ainda é pertinente lembrar que pouquíssimos acadêmicos sabem da origem do termo Estado de exceção e quem foi seu principal teórico; em contrapartida é uma expressão corrente nos ambientes universitários e de ensino, sendo a terminologia usada, em demasia, nos inflamados discursos políticos, como na imprensa em geral.

Ao final deste escrito, cabe indagar, afinal, qual o lugar de fala desse soberano? Com quem ele fala e de onde? A ideia é uma ruptura do direito vigente, de um limbo, onde autoridade surge como a entidade que vai expurgar todo mal, afastar onde não há "luz", onde o direito não se faz "direito". Ora, o estado de exceção é posto em debate justamente por um vazio no direito positivo, no direito posto, uma vez que o que está legislado já não responde às demandas conflituosas da realidade. Desse modo, diante de uma inoperabilidade do Poder Legislativo e de um não poder agir (competência) do Poder Judiciário, sobra para o representante do Poder Executivo preencher as lacunas (as anomias) e restabelecer a ordem do direito romano.

Em tempo que medidas executivas, legislativas e judiciais são deferidas e executadas, não raramente, com "as vestes" de uma exceção à norma vigente, cumpre a toda a comunidade acadêmica, "favorecida" pelo acesso ao conhecimento de qualidade produzido e fomentado em nossas universidades e faculdades, tomar ciência e debruçar sobre a temática tão cara ao nosso tempo.

\section{REFERÊNCIAS}

AGAMBEN, Giorgio. Estado de exceção. Tradução de Irani D. Poleti. 2. ed. São Paulo: Boitempo, 2004. 142p.

AGAMBEN, Giorgio. "O estado de exceção se tornou norma": o pensador italiano, que publica no Brasil 'O Fogo e o Relato', fala de filosofia, de arte, de poesia e da tendência política do mundo atual. [Entrevista cedida a Francesc Arroyo]. El País, Cultura, 30 abr. 2018. Disponível em:

https://brasil.elpais.com/brasil/2016/04/19/cultura/1461061660_628743.html. Acesso em: 14 jun. 2019.

D'URSO, Giacomo. A crise da representação política do Estado: perspectivas da soberania em Carl Schmitt, Michel Foucault e Giorgio Agamben. Barueri: Minha editora, 2016. 265p.

MARTINS, Lucas Moraes. O estado de exceção como um espaço vazio de direito. Pensar Revista de Ciências Jurídicas, Fortaleza, v.20, n.3, set./dez. 2015.p. 847-873. Disponível em: http://periodicos.unifor.br/rpen/article/ view/ 3102/pdf. Acesso em: 14 de jun. 2019.

MENDES, Gilmar Ferreira. Apresentação. In: SCHMITT, Carl. O guardião da constituição. Tradução de Geraldo de Carvalho. Belo Horizonte: DelRey, 2007. p. 11. 
SCHMITT, Carl. A crise da democracia parlamentar. Tradução de Inês Lohbauer. São Paulo: Scritta, 1996. 133p.

SCHMITT, Carl. O führer protege o direito: sobre o discurso de Adolf Hitler no Reichstag em 13 de julho de 1934. Tradução de Peter Naumann. In: MACEDO JUNIOR, Ronaldo Porto.

Carl Schmitt e a fundamentação do direito. São Paulo: Saraiva, 2011. p. 177-182.

SCHMITT, Carl. O nomos da terra: no direito das gentes do jus publicium europaeum. Tradução de Alexandre Franco de Sá, Bernardo Ferreira, José Maria Arruda e Pedro Hermílio Villas Bôas Castelo Branco. Rio de janeiro: Contraponto, 2014. 351p. 